\title{
Thoracic Aorta
}

National Cancer Institute

\section{Source}

National Cancer Institute. Thoracic Aorta. NCI Thesaurus. Code C33766.

The section of the aorta between the lower border of the fourth dorsal vertebrae and the aortic opening in the diaphragm. 